\title{
LA HISTORIA COMO DISCURSO DE IDENTIDAD. LA DOMINACIÓN Y «EL ARTE DE LA RESISTENCIA» ENTRE LOS GARÍFUNAS DE GUATEMALA
}

\author{
Nancy Martínez \\ mnancye@yahoo.com \\ Centro de InVEstigaciones y Estudios SuPERIores \\ EN ANTROPOLOGÍA SOCIAL \\ MÉXICO
}

\begin{abstract}
No hace mucho tiempo, la tierra estaba poblada por dos mil millones de habitantes, es decir, quinientos millones de hombres y mil quinientos de indígenas. Los primeros disponían del Verbo, los otros lo tomaban prestado Jean Paul Sartre ${ }^{1}$
\end{abstract}

\begin{abstract}
RESUMEN
El presente texto discute cómo «la historia» es utilizada discursivamente para reafirmar una identidad y legitimar, al mismo tiempo, una presencia, un proceder en un momento coyuntural. Entre los garífunas, sucedieron a la firma de los Acuerdos de Paz (1996) una serie de discursos sobre su origen y permanencia en el país. Cómo iniciaron y la ascendencia, provenir o no de África, así como tener o no sangre caribe, eran cruciales para tratar de comprender la propia identidad en el contexto nacional guatemalteco. Al mismo tiempo, estos argumentos son un contínuum de resistencia dada desde la dominación colonialista. Así, los postulados de James C. Scott (2004) y de Franz Fanon (1973) resultan pertinentes para enmarcar de forma teórica una situación de dominación que continúa para el pueblo garífuna dentro de la nación guatemalteca.
\end{abstract}

Palabras clave: Garífunas, identidad, historia oral, resistencia.

\footnotetext{
${ }^{1}$ Frantz Fanon, 2003, prefacio de Los condenados de la tierra. FCE, México.
} 


\begin{abstract}
This text discusses the way «history» is used discursively to reaffirm identity and at the same time to legitimize a presence and a modus operandi at a particular time. Among the Garinagu, the signing of the peace agreements in 1996 was followed by a series of discourses on their origin and permanence in the country. Origin and ancestry, whether or not one came from Africa or had Carib blood, were crucial to understanding identity in the Guatemalan national context. At the same time, these arguments form part of a continuum of resistance that has taken place since the time of colonial domination. The postulates of James C. Scott (2004) and Franz Fanon (1973) are significant in providing a theoretical framework for a situation of domination that continues for the Garinagu people within the Guatemalan nation.
\end{abstract}

Key words: Garinagu, identity, oral history, resistance. 


\section{INTRODUCCIÓN}

En este ensayo propongo hacer una reflexión acerca de la historia como un instrumento ideológico de identidad entre los dominados, para ello se retoman algunos de los planteamientos que hace James C. Scott en su obra Los dominados y el arte de la resistencia. Discursos ocultos (2004), así como en general los de Frantz Fanon en Piel negra, máscaras blancas (1973). Si se considera el hecho de que la historia es un discurso, observaremos cómo esta se reinventa y sirve para determinados fines. Así, hay entre los garífunas, pueblo afrodescendiente de Guatemala, la construcción de una historia de resistencia sobre su pasado que se trasmite y circula de forma oral; por otro lado, coexiste con ésta y otras historias orales una «historia oficial» que han escrito antropólogos e historiadores, casi siempre extranjeros. Las dos historias o discursos destacan sucesos importantes para explicar quiénes son los garífunas; por un lado, la historia oficial marca una cronología basada en los archivos; por el otro, la oralidad marca una relación espacio-temporal que es pasado y presente al mismo tiempo, un aquí y ahora, un presente continuo. El momento para expresar dicho discurso de identidad se da en los años inmediatos a 1996, después de la firma de los Acuerdos de Paz en Guatemala.

El hecho fidedigno es prescindible para la memoria histórica en la oralidad, pues el sentido que da este pueblo a su propia historia es ideológico. En este tenor, un punto de análisis es observar cómo la historia sirve para reivindicar a un pueblo, y cómo la memoria histórica es la base para legitimar la propia identidad del ser garífuna. De esta manera, la clásica pregunta ¿historia, para qué?, se vincula también con otra que cuestiona por qué existe la necesidad de tener una historia. A estos planteamientos se suman otras variables de análisis, como el lugar que ocupan los garífunas como pueblo dentro de la nación guatemalteca; asimismo, el racismo constituye un punto fundamental que complejiza la utilización del discurso histórico.

Explicar el pasado sirve para construir una identidad, de otra manera no tendríamos familia ni ancestros ni una patria. La historia es una memoria y la historia en la memoria forma parte de una cultura de la resistencia para muchos dominados. La gente que cuenta su propia historia, generalmente no tiene por objeto verificar científicamente si los hechos ocurrieron como se dicen; lo significativo para ellos es demostrar un vínculo con el pasado, una sucesión de hechos que legitiman el estar ahora 
en determinada situación. Recordar a los héroes con sus hazañas tiene la finalidad de ejemplificar también conceptos morales y de justicia. Discursivamente, el narrador es un yo del presente que vive al mismo tiempo el pasado con los ancestros en una sucesión espacio-temporal que se conforma en un nosotros.

Adolfo Gilly (1995: 179) citaba a Vico diciendo que la historia de la humanidad se diferencia de la natural en que la primera la hemos hecho nosotros; además decía que su objeto privilegiado es la descripción y el conocimiento de las relaciones sociales y de sus trasformaciones (Gilly 1995: 199). Así, sin más pretensiones que explicar el pasado para saber quiénes son y por qué viven en Guatemala, los garífunas preocupados por su identidad cultural repiten una y otra vez cómo surgieron los garínagu — plural de garífuna-, las guerras con los europeos, el exilio hacia Honduras y el arribo a Guatemala. El discurso histórico garífuna es, sobre todo, una historia de reivindicación para ubicar su lugar en la historia universal y nacional; sirve también para explicarse a ellos mismos y a los otros, justifica su lugar en el mundo.

\section{DISCURSO HISTÓRICO GARÍFUNA}

Acerca de la historia propia existen varias versiones, pero hay al menos dos que resultan importantes por su trasfondo ideológico, pues revelan y explican ciertos detalles sobre el origen de los garífunas. El lugar de la etnogénesis se sitúa en la isla de San Vicente, Yurumein en garífuna, donde ocurre la mezcla racial y cultural entre africanos y caribes.

Una versión muy común dirá en primer término que los garífunas vienen de la isla de San Vicente, que llegaron de África en un barco negrero, mas hubo una revuelta y los garífunas mataron a los europeos, después atracaron en San Vicente y allí se aliaron con los caribes donde tomaron por esposas a las mujeres.

Otra historia dice que los ancestros garífunas venían directamente de África sin intervención de los europeos, porque ellos ya conocían rutas de navegación a América; en esta versión se menciona un naufragio, causa por la que llegaron a San Vicente, donde mataron a los caribes varones y se quedaron con las mujeres.

Así observamos que la historia producida por los garífunas se centra en la africanía, es decir, se busca establecer un vínculo con África; estas dos versiones refieren al ser garífuna como africano, en la primera versión los garífunas vienen de África como esclavos y matan a los europeos, no a los caribes; en la segunda, no fueron 
esclavos sino hombres temerarios que matan a los caribes para obtener a sus mujeres después de un naufragio; en ambas explicaciones, el hecho de unirse con las mujeres caribes parece circunstancial, se presenta sobre todo una historia de hombres africanos.

La segunda parte de la historia después del origen de los garínagu es más uniforme, se refiere a la lucha contra los ingleses, la deportación a Honduras, y al arribo y fundación de Livingston, Labuga en garífuna, donde aparece un líder llamado Marcos Sánchez Díaz.

Según la versión generalizada Yurumein era una isla muy bonita, por lo tanto codiciada por los europeos. Fueron los ingleses quienes les hicieron la guerra a los garífunas hasta que finalmente los expulsaron llevándolos a la isla de Roatán, en Honduras. Ya ahí, los españoles les dieron permiso de llegar a Trujillo, pero con las luchas de independencia algunas familias decidieron irse, como eran navegantes conocían ya muy bien la costa atlántica, fue de esta manera como Marcos Sánchez llevó a algunas familias hasta Labuga.

La parte referida a los ancestros es importantísima, ya que revela a los labugueños los orígenes compartidos entre ellos; por ejemplo, Sánchez es un apellido muy común, son los descendientes del líder Marcos Sánchez Díaz.

Así, entre la sociedad garífuna se conoce muy bien el linaje por los apellidos, y regularmente el hombre «reconoce» —oficialmente ante el registro civil— a sus hijos aunque no viva con ellos.

Es importante destacar la figura de los ancestros líderes, pues son los antepasados quienes todavía guían la vida de los garífunas. Además de Marcos Sánchez, de quien se dice que era un shaman, está el líder Satuyé que luchó contra los ingleses, y por supuesto tiene descendencia. Es una mítica figura relacionada con Yurumein, el lugar del origen. De él se dice que era un gran estratega, políglota y polígamo, como lo eran entonces todos los garífunas. Ambos líderes todavía guiaban la vida de su pueblo a través de los sueños.

La historia de la fundación de Labuga o Livingston también tiene sus variaciones. Hay una historia sobre la fundación, y dos acerca del nombre.

Se dice que estando en alta mar los garífunas buscaban un lugar para vivir cuando de pronto vieron una luz resplandeciente. Al acercarse, descubrieron que venía 
de tierra firme, descendieron, mas al acercarse disminuía su intensidad, hasta que al llegar a ella vieron que era una piedra que tenía la figura de un «pescadito fosilizado».

¿Por qué se llama Livigston o Labuga? Se llama Livingston porque allí vivió un viajero inglés apellidado Livingston, el gobierno lo reconoció como el fundador y registró el municipio con este nombre, para algunos es también un ancestro que se comunica con ellos, aunque es blanco.

Se llama Labuga porque estando en las circunstancias de buscar nuevas tierras para habitar, alguien dijo: «vamos hacia Labuga», es decir, la boca, porque Livingston está rodeado de agua casi por todos lados, el mar y la desembocadura del Río Dulce; por lo tanto, es la boca del río. Esta historia coloca a los garífunas como los pobladores originales de Livingston, algo parecido a la tierra prometida de algún pasaje bíblico. Es una tierra que de alguna manera ya estaba destinada para ellos después de haber padecido el desarraigo de Yurumein. La guerra y el exilio son circunstancias que la memoria histórica retoma para legitimar ¿por qué estamos aquí? Y para responder ¿de dónde venimos?

\section{DISCURSO HISTÓRICO OFICIAL}

Bonfil Batalla (1995: 229-245) comenta que hay historias que no son todavía historias porque simplemente ocupan un lugar marginal en la historia de los otros, de los dominantes.

Revisando la historia oficial, la escrita por los antropólogos e historiadores que se basan en fuentes «fidedignas», observamos que también existe la referencia a un naufragio, a la lucha contra los europeos, y la deportación a Honduras. Salvador Suazo - historiador garífuna hondureño que retoma las fuentes coloniales escritas por los europeos - en Los deportados de San Vicente (1997), también apoya esta versión.

La historia documentada reconoce a los garífunas como descendientes de los llamados, durante la colonia, caribes rojos o amarillos —red o yellow Caribs_-, de lengua arahuaca, quienes a su vez se mezclaron con los caribes isleños y se llamaron kalibis, galibis, kallinago; es posteriormente cuando hacen alianzas matrimoniales con los africanos y se les empieza a conocer como black Caribs o caribes negros; coexistiendo dos facciones caribes: la negra, de la mezcla con africanos; y la amarilla o roja, sin mezcla. Los científicos coinciden en que sí ocurrió un naufragio hacia 1625 
entre Becquia y San Vicente. Coinciden también en que los caribes fueron un grupo que resistió a los españoles, por lo que la alianza entre los dos grupos, negros e indios, era estratégica. Los europeos se disputaban el control de las islas caribeñas, primero españoles, luego holandeses, ingleses y franceses; fueron los dos últimos quienes lucharon por la isla de San Vicente. Lugar donde habitaron también los piratas quienes hacían intercambios comerciales con los caribes. Finalmente, los ingleses obtienen «legalmente» el derecho sobre la isla, gracias a un juicio entre potencias europeas, y después de varias luchas contra los franceses y contra los caribes deciden capturar a todos los caribes negros y llevarlos a la isla de Roatán, pues era de igual manera una isla disputada entre ingleses y españoles. Los garífunas se alían con los españoles y se quedan a vivir en Trujillo.

Las historias de los garínagu después se particularizan según el lugar donde actualmente vivan: Honduras, Nicaragua, Belice o Guatemala. Cada población posee la historia de sus líderes o fundadores, cada una es única, pues se diferencia de otra localmente y por su nacionalidad administrativa — beliceña, guatemalteca, hondureña, o nicaragüense.

\section{UN DISCURSO DE RESISTENCIA}

Comparando las versiones históricas, orales y escritas, observamos que los garífunas en su memoria han adaptado los sucesos ocurridos en su interacción social —con la otredad - a una ideología muy particular que plasma su manera de ver el mundo. En primer lugar, resalta su negritud, y por tanto la minimización de lo indígena frente a su ascendencia africana. Sin embargo, esta ideología se ha complejizado en los últimos años con el reconocimiento de indígenas, al igual que los mayas, por parte del gobierno guatemalteco en los acuerdos sobre identidad, contenidos en los de paz. Hacia 1998, aproximadamente, no había una aceptación sobre el nombramiento oficial del ser indígena entre la población en general. Todavía hoy, el común de los garífunas labugueños difícilmente se identificará o se dirá indígena o indio; pero con la apertura del gobierno para incorporar en su equipo elementos indígenas garífunas, algunos líderes comenzaron a utilizar el mismo discurso de identidad sobre el origen de su pueblo, destacando su ascendencia caribe. Así, observamos que es posible tomar el control de la historia para decir o decidir quién es uno. 
Por otro lado, mientras que la historia oficial afirma que los africanos de San Vicente probablemente eran cimarrones que escapaban de la esclavitud, los garífunas afirman: «nosotros nunca fuimos esclavos». Para un garífuna existe la diferencia entre sí mismos y el guiou, el otro negro, el que ante sus ojos sí fue esclavo.

La interpretación sobre la propia historia que se refiere a su procedencia, donde se afirma que los garífunas «vienen de África», se puede explicar sencillamente si consideramos que la noción común sobre la conformación étnica en Guatemala ratifica que los negros vienen de África, los blancos de Europa, y los indios son los nativos de América. En medio de un clima de discriminación racial, los garífunas saben que los negros vienen de dicho continente, y autopercibiéndose como negros asumen simplemente que vienen de allá; la oportunidad para reivindicarse la encuentran al demostrar discursivamente que llegaron no como esclavos sino como navegantes, porque eran hombres de conocimiento. A este respecto hay la siguiente versión de un garífuna radicado en Nueva York:

\footnotetext{
In the early 1300s, the Mali Empire was the leading country in technology. King Abubakari, brother of Mansa Musa the emperor, ventured on a journey to expand trade and commerce with other countries. With over two thousand sailors, Abubakari sailed away with ships laden with precious stones, gold, fruits, plants and agricultural tools. During the journey, these brave sailors separated and drifted apart. As a result they landed in the Americas and the Caribbean. Take note, that this great African accomplishment took place before Columbus accidentally landed in the Caribbean august 12th, 1492. The Africans came in peace, sharing their knowledge with the red Caribs and Arawaks. The Africans who eventually remained in the Caribbean intermarried into the Caribs and Arawaks. Since the Africans have different characteristics from that of their hosts, their offspring were dark in complexion, had coarse hair, a slender build and an average of 5 feet 9 inches in height. Eventually, these new offspring would become known as the Black Caribs or the Garifuna People (Lowell James 2002).
}

Retomando a James Scott, un discurso oculto puede ser no solo el que no se dice en público sino también aquel que se dice oculto para los demás, con señas, con ciertas palabras o gestos. Pero, si los lenguajes fueran del todo ocultos nadie los sabría, entonces, podríamos pensar que son ocultos sobre todo para quienes no quieren verlos ni oírlos, pues se expresan sutilmente; sin embargo, hay otros discursos que se ocultan bajo el discurso propio, aquel dicho en la lengua materna, que será ininteligible para los 
extraños, para los otros. En el fragmento arriba expuesto por Lowell, es explícita su ideología de resistencia a ser aquello que los otros quieran que ellos sean. De esta manera, los garífunas se asumen como negros pero no como esclavos, y ese es su mayor orgullo, igual que el haber luchado contra los europeos. Para ellos su historia no está acabada, comenzó apenas ayer y continúan la búsqueda de un lugar en el mundo. Éstas «... no son historias concluidas, ciclos terminados de pueblos que cumplieron su destino y "pasaron a la historia", sino historias abiertas, en proceso, que reclaman un futuro propio» (Bonfil 1996: 229).

Ha sido importante para los garífunas explicarse a sí mismos quiénes son, y es sobresaliente que haya ocurrido marcadamente en el contexto de la firma de los Acuerdos de Paz guatemaltecos en 1996. El discurso oficial los reconoce indígenas y ellos responden argumentando por qué lo son o no. Finalmente, la aceptación del ser indígena ha tenido que ver con una situación práctica. El ser negro es una identidad que siempre ha sido reconocida por sí mismos y por los otros, el ser indígena les ha otorgado un matiz distinto que los incorpora a la nación guatemalteca que se dice pluricultural y multilingüe. Sin embargo, la invisibilización de los garífunas al interior de un Estado nación guatemalteco que se había declarado tradicionalmente sustentado en «la cultura» indígena - maya-ladina-, de alguna manera vuelve a presentarse al nombrarse indígenas a los garífunas, pues las historias y las culturas de los otros indígenas - los mayas — son distintas y difícilmente compartidas entre sí.

En general, «la historia guatemalteca» no ha reconocido a los garífunas como parte de la nación. El conflicto étnico en el país se ha centrado específicamente entre ladinos e indígenas de origen maya. Si bien Severo Martínez Peláez habló en su obra célebre La patria del criollo..., sobre el componente africano en la sociedad nacional, hasta la fecha tal vez no se ha hecho ningún esfuerzo de inclusión de los garífunas en la historia nacional, ni siquiera merecen un lugar obras recientes que hacen directa alusión al tema de las relaciones interétnicas y la nación multicultural en Guatemala.

En consecuencia, entre algunos garífunas ha persistido un sentimiento de exclusión por parte de la nación guatemalteca, pues ellos no se identifican ni como indígenas ni como mestizos o ladinos. En cambio, mediante esfuerzos conjuntos de algunos líderes con organizaciones «negras» de Centroamérica se han logrado 
identificar como «personas afrodescendientes y pueblos afroamericanos» a todos los negros de América (Oneca 2000).

Aproximadamente, dos décadas antes, un sobresaliente líder declaró:

La verdad es que nosotros no nos consideramos ni indígenas ni ladinos. Somos garífunas. Entonces nos preguntamos ¿dónde estamos nosotros? ... ¿me siento más guatemalteco o más negro? ... Si me preguntan de qué nacionalidad soy, diré que soy guatemalteco, pero me siento de nacionalidad garífuna. Este es un sentimiento general entre nosotros (Mario Gerardo Ellington 1989).

En este discurso, la resistencia garífuna se centra en resaltar que la nación guatemalteca basa su identidad en el binomio indígena-ladino del cual ellos están excluidos, pues el ser negro o el ser garífuna no entra dentro de esta conformación identitaria nacional. Ante tales circunstancias, la respuesta es de extrañeza por el ser guatemalteco, pero una reafirmación del ser garífuna.

La historia nacional u oficial plantea a los garífunas la necesidad de hacer su propia historia con el fin de diferenciarse de «los guatemaltecos». ¿Qué representa para los garífunas no estar ahí? Si «los guatemaltecos» han borrado a los garífunas de la nación, a estos les queda el camino de la reafirmación de la identidad étnica y la adscripción a una nación garínagu.

El culto a los ancestros igualmente funciona como una memoria que expresa la continuidad del ser garífuna, una base que sustenta su proyección en la vida y su razón de estar en el mundo. Es un estrecho vínculo pasado-presente, que a veces se piensa sólo presente y que finalmente se vive desde el aquí y ahora. Los ancestros que continúan viviendo a través de los sueños y de los buyei guían la vida de sus descendientes. Bonfil Batalla (1995: 239) menciona que la historia de los indígenas no es lineal como la conciben los occidentales sino cíclica, pues es vista como una sucesión de ciclos que se cierran a través del tiempo. Esta posibilidad de concebir la historia o los acontecimientos de una manera distinta a la forma de inventarla en occidente, permite acercarnos con otra mirada al discurso sobre la propia historia garífuna. 


\section{¿HISTORIA, PARA QUÉ?}

Los garífunas son uno de los pocos pueblos dominados que han retomado su historia como instrumento de reivindicación. Es un pueblo que cuenta con líderes preparados profesionalmente, en su mayoría hablan dos o tres lenguas, en general, sostienen sus fiestas tradicionales y a su gente gracias a las remesas que envían los parientes desde Estados Unidos; algunos líderes tienen grandes planes hacia el futuro, están luchando por salvaguardar su cultura, por mantener sus tierras y su lengua.

El ser negro para algunos de los garífunas de Livingston abre la posibilidad de tener un origen auténtico, mientras que si se asumiesen como indígenas no tendrían ningún elemento discursivo para legitimar su lugar entre el resto de los indígenas mayas, pues en Guatemala el ser indígena y maya comúnmente funcionan como sinónimos.

El sentido de explicarse de dónde han venido es un principio de identidad. La necesidad de marcar un distanciamiento con los indígenas mayas del país fue imprescindible en un momento de coyuntura política, cuando discursivamente se les reconoció como parte de la nación.

A través de los discursos sobre la propia historia garífuna su destino comienza a tomar forma, y en los primeros años después de la firma de la paz el ser guatemalteco fue una cuestión a reflexionar, pero también el ser indígena y negro. Utilizar un discurso de identidad «negro» parecía reforzar ese origen para hacer contrapeso a un nominativo externo.

Guatemaltecos son los habitantes de un territorio, pero la idea de nación no ha logrado contener la diversidad étnica del país. Indígena o ladino no alcanza a definir al garífuna. Estando ausentes en la historia oficial de la nación, no tienen cabida. Su participación en los sucesos trascendentales del país es nula, la pasada guerra no afectó - como a la población maya - a la comunidad garífuna, que sin embargo se vio beneficiada con el reconocimiento político en los Acuerdos de Paz — «tuvo que venir una india, Rigoberta Menchú, a decir: "allá tenemos a nuestros hermanos garífunas"»-. En el discurso político oficial, los garífunas y su cultura han ganado reconocimiento, hecho que ha servido a los gobernantes para proyectar en el ámbito internacional que Guatemala vive un cambio de modelo estatal, aunque al interior las cosas no marchen 
como habría de esperarse: el racismo y el monopolio del poder entre los grupos oligárquicos son de los principales obstáculos.

El sentido de hacer y recrear una historia propia responde al hecho de la exclusión histórico-política dentro de la nación, pero también a la posibilidad de tomar las riendas de su propio porvenir. Reivindicar un origen «negro», en un momento en que políticamente lo indígena cobraba un valor importante, es un acto de resistencia que se vuelve a apagar cuando los embates del poder les imponen límites de acción. Finalmente, si no se asumiesen como indígenas romperían con el modelo cultural, social, histórico y político hegemónico del país: indio-ladino.

Por otro lado, si la historia de Guatemala no los reconoce, queda la opción de buscar cabida entre la historia de los rebeldes, de los que nunca fueron esclavos. En este sentido la historia de los caribes, que fueron los últimos nativos de las Antillas en ser sometidos, les refuerza este estandarte de rebeldía y resistencia. Lo mismo el discurso que reivindica a los garífunas como navegantes provenientes de África, o a aquellos que se hicieron cimarrones.

\section{DOMINACIÓN DENTRO DE LA DOMINACIÓN}

Para Scott (2004: 52), entre los subordinados existen también mecanismos de control entre ellos mismos, «el preso subordinado debe medir sus palabras y su comportamiento más cuidadosamente ante los presos dominantes que ante las autoridades de la prisión». Es decir, que entre los subordinados existen ciertas normas de conducta no explícitas pero por todos conocidas. De esta manera, ideológicamente un garífuna sabe que pertenece al grupo garífuna, a la raza negra o a Guatemala. Esta relación se puede observar desde la identidad y desde el poder. Quién es quién se marca por un aspecto relacional, tiene que ver con la identidad, de alguien se espera una determinada conducta si es garífuna, hombre o mujer, joven o viejo; de la misma manera, el poder tiene que ver con ese lugar que cada quien ocupa socialmente: cuándo estar de qué lado, en qué circunstancias.

Un hombre que ha tenido mujeres blancas será visto con desdén entre las mujeres garífunas. Un caso muy especial de un hombre ladino que se crío entre los garífunas y aprendió su lengua, se encuentra a veces en situaciones muy contradictorias, como el hablar bastante mal acerca de los negros, mientras que entre ellos tiene a sus 
mejores amigos. Al mismo tiempo que los garífunas le llaman indio, le permiten participar de ritos o ceremonias exclusivas para garífunas. Es otro que de alguna manera es un nosotros, que puede ser reprendido sobre todo cuando se le mira acompañado de mujeres blancas.

En otro ámbito muy general, el garífuna se identifica con la nación guatemalteca en declaraciones como: «Belice es nuestro». Cotidianamente se puede escuchar que hable de «los guatemaltecos»y de «nosotros los garífunas», en otro momento dirá «los inditos». Y cuando regrese de «los Estados [Unidos]» se sentirá superior al resto de sus paisanos. Es muy fácil identificar a los que vienen de «los Estados» pues visten con pantalones, tenis, calcetines, pulseras y cadenas de oro. En contraste, los que viven en Livingston visten con bermudas, chanclas, no traen adornos y mucho menos dinero. Por un lado, está la ostentación del poder - adquisitivo- aunque no son millonarios, y seguramente, como la mayoría de los migrantes en Estados Unidos, realizan trabajos técnicos que son mejor remunerados allá que en el propio país; con ese dinero, cuando vuelven, los parientes tienen la obligación de invitar por lo menos un trago a los que se quedaron. El compartir y ayudarse entre los miembros de la comunidad es un valor socialmente establecido entre los garífunas, de manera que quien no lo realiza es sancionado por su falta a través de los rumores entre los demás.

Por otro lado, existe también un nivel comparativo entre los dos países - Guatemala y Estados Unidos_- ; volver de uno poderoso, hablar inglés y tener dinero, son valores que los dominantes o colonizadores han sabido inculcar a los dominados. Ideológicamente, Estados Unidos representa para muchos garífunas una posibilidad de ascenso social y económico. Muchos esperan la posibilidad de poder ir allá, o a algún país europeo, en busca de «mejorar», lo cual no siempre sucede. La discriminación entre los negros del mundo existe. Es sabido que los negros neoyorquinos discriminan a los garífunas por ser latinos, mientras que al interior de su nación luchan por la no segregación.

El hecho de la discriminación, o de la interiorización de la dominación hacia otros dominados, es un fenómeno muy recurrente. Por un lado existen las denuncias sobre racismo o discriminación, mas en la cotidianidad las cosas son bastante complejas. En el caso garífuna este aspecto se ve reflejado en las relaciones interétnicas 
donde los garífunas, los ladinos y los q'eqchi' reproducen el discurso dominante, se lo apropian y lo utilizan para discriminarse entre sí.

«Negro» en muchos casos es casi un insulto, de la misma manera que «indio», y ambas categorías se utilizan cotidianamente para ofender a los otros, al mismo tiempo que en diversos ámbitos se utilizan como reivindicación; así, podemos oír que se habla de «pueblos indios» o de «organizaciones negras». Los garífunas de Belice han sabido aprovechar la acepción Indigenous People para obtener ciertos derechos; mientras que en Nicaragua, con el surgimiento de la Región Autónoma del Atlántico Sur, RAAS, y la posibilidad del apoyo con financiamiento internacional, los garífunas, quienes ya habían abandonado casi por completo su lengua, han hecho proyectos para recuperarla, pues en este contexto también les conviene ser Indigenous y no Creole - negros anglófonos o guiou.

En Guatemala, el término no ha tenido la misma suerte, ser indio o indígena no ha gozado de buena reputación, además, comúnmente se sabe que los indígenas son los de origen maya. Así, en los últimos tiempos se ha reconocido en Guatemala un uso despectivo de la palabra y se ha sustituido por «maya». En otro sentido, los líderes garífunas que en los últimos años se han apropiado de este nominativo han dado al concepto el sentido de «indígenas» como pueblos originarios de América. En este punto, el origen caribe-arahuaco de los garífunas funciona para legitimar ahora un lugar dentro de la nación guatemalteca. Sin embargo, entre la gente común, difícilmente alguien diría que un garífuna es indígena, y aun ellos mismos también se autoidentificarían como garífunas, morenos o negros.

Sabiendo el uso despectivo de indio, los garífunas tienen una percepción muy fina sobre las características físicas y culturales de este tipo. Comer chile y tortillas es propio de los indios; tener cabello liso y tieso es tenerlo de indio, pronunciar mal el español es «hablar como indito». Ser indígena o indio no es positivo, es lo que socialmente nadie quiere ser. Un hombre garífuna contaba que «los indios quieren dejar de ser indios». Una «india» llegó a vivir con él; al cabo de unos meses nació su primer hijo, cuando vio que era moreno — negro—, ella dijo: «mi hijo ya se salvó».

Por su parte, algunos garífunas también tienden a buscar la manera de blanquearse; cuando nace un niño y es «más blanquito» que los demás lo dicen con orgullo, pero al mismo tiempo será rechazado en la comunidad con el despectivo 
«indio»: «vos, sós indio». Así, vemos una vez más cómo se manifiesta la represión entre los propios dominados — como señala Scott—; por un lado, pervive una admiración hacia el poderoso, por otro un rechazo. «Cualquier respuesta a un todopoderoso será una combinación de idealización y odio» (Scott 2004: 65). El ejemplo más claro lo encontramos entre algunos «rastas» de Livingston; el discurso de éstos es ambivalente y contradictorio ya que proclaman su afrodescendencia de grandes civilizaciones como la egipcia, y a la vez rechazan a los inditos, a los «caras pálidas» — todos los que no son negros_- pero se les puede ver con novias «gringas» — blancas.

Es preciso subrayar un control ideológico impuesto por la colonización del mundo occidental en América. Suele pensarse en la época colonial como cosa del pasado, sin embargo, la pregunta sobre una colonización ideológica es pertinente, posiblemente son remanentes de aquella época, lo cierto es que nuestros países continúan siendo monitoreados por los dominantes a través de los mensajes enviados por medios de comunicación como la radio, la televisión y la prensa. Pudiera ser que ahora se piensa en globalización, de cualquier manera, en esta nueva era también hay dominantes y dominados; la periferia, el tercer mundo, están en el mismo sitio desde entonces. Fanon mencionaba en su obra Piel negra, máscaras blancas cómo ir a Francia era de lo mejor entre los martiniqueses, se preparaban tratando de hablar excelentemente para que no se les notara el patois, asimismo, quien regresaba de allá era admirado, y éste procuraba sólo hablar francés a los amigos. Por otro lado, en el medio francófono un martiniqués era inferior a un francés, pero en todo caso era mejor que un africano.

De esta manera la dominación entre los dominados pesa mucho, también tiene que ver con lo que Scott llama «actuación», con el deber actuar como patrón y como subordinado; con una conducta pública conducida por los dos, pero que al interior de sus respectivas comunidades se desactiva, pues cada quien ocupa allí otro lugar y vuelve a actuar de otra manera, pero sin que se pierda ese referente de poder, pues aquí también, como hemos observado, las conductas de dominio se repiten hacia los demás dominados. Frantz Fanon (1973) hablaba de un blanco interiorizado que llevan los colonizados, el cual era difícil de identificar y de quitárselo; James Scott (2004: 59), dice que hay «un discurso público que aparentemente reconfirma la ideología social de los dominadores. Los subordinados hacen reverencias y venias, dan la apariencia de ser 
respetuosos, de ser amables, de saber cuál es su lugar y de aceptarlo, indicando con ello que también saben y aceptan el lugar de sus superiores». Scott habla de igual manera de la dominación entre los dominados, donde el sujeto en su actuación se parece mucho a la descripción que Fanon hace sobre las máscaras blancas. Sin embargo, mientras Scott habla de los discursos ocultos que denotan que los dominados actúan así para aceptar su lugar públicamente, Fanon va más allá y muestra que la dominación logra penetrar hondamente en los sujetos y que ésta es así más que una actuación pública una adjudicación del poder para reproducirlo cuantas veces sea posible. Por ello, logran coexistir los discursos ocultos con la interiorización del poder.

\title{
DOMINACIÓN Y SUBORDINACIÓN
}

\author{
¿Quiénes y cuáles somos? ¡Admirable pregunta! \\ A fuerza de contemplar los árboles me he convertido en un árbol \\ y mis largos pies de árbol han cavado en suelo \\ anchos sacos de veneno altas ciudades de osamentas \\ a fuerza de pensar en el Congo me he convertido \\ en un Congo rumoroso de bosques y de ríos
} Aimé Césaire (1969: 61)

Dominación no implica necesariamente el uso de la fuerza, el elemento psicológico suele ser más fuerte para el efecto, «... los grupos excluidos reciben, sea directamente o por omisión, una visión humillante de sí mismos, como si toda la creatividad y la valía sólo proviniesen de los varones europeos» (Taylor 2001: 97), o de occidente en general. Por omisión es posible observar que «la belleza» no corresponde al prototipo indígena o negro. El modelo dominante de belleza corresponde al europeo. En general, los hombres y mujeres que vemos en los anuncios publicitarios son esbeltos, altos y rubios. El mensaje implícito es que los morenos, bajos de estatura y robustos, son feos. Ser moreno o negro representa en la actualidad como en la época colonial: ser de una casta inferior en la escala social y humana.

En el caso garífuna la dominación se presenta en varias dimensiones, en una está el espacio nacional, que tiene que ver con su situación de «grupo étnico»; la otra, tiene que ver con lo racial, con el lugar que ocupa ideológica y socialmente lo blanco y lo no blanco - los indígenas y los negros - Esta dominación se manifiesta, sobre todo, como discriminación racial y exclusión social. 
La dominación entre los sujetos está interiorizada de tal manera que se vive como una condición natural, a veces es difícil observarla o ser concientes de ella. Es en todo caso una condición de ser. Fanon (1973: 8) afirma: «si yo quisiese ganarme a pulso el resentimiento de mis hermanos de color, yo diría que el Negro no es un hombre»; es decir, que el ser humano en esta condición está negado porque no es conciente de su ser, sino que está en un hoyo de exclusión, instalado en su negrura, de donde le es difícil salir porque está enajenado de sí mismo, su esperanza está en liberarse del ser negro que le fue impuesto. Dejar de serlo a través de la adquisición de la cultura dominante es uno de los caminos comunes.

Al considerar que «nuestra identidad se moldea en parte por el reconocimiento o por la falta de éste; a menudo, también, por el falso reconocimiento de otros ... un individuo o grupo de personas puede sufrir un verdadero daño, una auténtica deformación si la gente o la sociedad que lo rodean le muestran, como reflejo, un cuadro limitativo o degradante o despreciable de sí mismo» (Taylor, Charles 2001: 4344). Así, siguiendo a Taylor, podríamos afirmar que «por omisión» del Estado los garífunas no fueron parte integral de la nación guatemalteca sino hasta la firma de los Acuerdos de Paz, y «directamente» han sido discriminados por su color de piel en distintos ámbitos — los ejemplos sobran para demostrarlo-; también por su cultura.

Bajo tal dominación, sin embargo, los garífunas han sabido movilizar, desde la subordinación, su capacidad de agencia para reivindicar su lugar en la historia de Guatemala. El haber repensado su propia historia funcionó para reafirmar una identidad cultural que a veces se cree en peligro de extinción. Reforzar el aprendizaje de la lengua materna, en forma oral y escrita, así como reflexionar acerca de los aspectos que los hacen ser garífunas, fueron temas promovidos por los líderes para hacer frente a los embates de la dominación ideológica sembrada por el poder a través de la escuela y los medios de comunicación.

Occidente, hasta hoy, continúa dictando las formas culturales adecuadas; en nuestros países, por ejemplo, el aprendizaje y uso del idioma inglés se impone como necesidad para acceder a un puesto de trabajo o estudio. Entre mucha gente este idioma se considera superior al español, y a su vez es asumida la superioridad de éste frente al desprestigio de las lenguas indígenas; lo mismo ocurre con el color de piel, de ojos, de cabello, la estatura, la comida, el vestido, la vivienda, la tecnología, etcétera. 
De acuerdo con Scott (2004: 109), la hegemonía ideológica se da cuando el dominado tiene la esperanza de llegar a ser como el dominante, ya que esto «promueve la paciencia y alienta la imitación». Entonces, el subordinado acepta su lugar, pero cree que alguna vez podrá ser como el dominante. Es lo que Fanon nos hace observar en cuanto a llevar un blanco por dentro. En este sentido el negro quiere ser como el blanco, aunque al mismo tiempo sienta rechazo; por ese reflejo de imitación tiende a adoptar la cultura occidental. Esto lo podemos ver expresado entre algunos garífunas en la disposición al uso del inglés, la construcción de casas de block, el buscar una pareja «blanca», el abandono de los cultos ancestrales, de la lengua materna, de la música y los bailes. En general, cuando algún garífuna alcanza «el éxito» marcado por esa ideología dominante, y siguiendo las pautas discriminatorias de su sociedad, normalmente se siente superior al ladino: el «blanco» de Livingston; pero dentro de este círculo vicioso, el ladino continuará despreciando al negro, al mismo tiempo que sentirá admiración por las potencialidades de éste, entre otras, el favoritismo de «las gringas», quienes representan a su vez lo dominante, la proveniencia de un país, de una cultura y de una raza superiores.

\section{RESISTENCIA Y LIBERACIÓN}

Para Frantz Fanon, tanto el blanco como el negro padecen de narcisismo, «el blanco está encerrado en su blancura. El negro en su negrura ... al calor de una serie de aberraciones afectivas, se ha instalado en el interior de un universo del que bueno sería hacerle salir» (1973: 8-9). La tarea, nos dice, será liberar al negro de sí mismo; deberá ser conciente de que negro es una construcción ideológica creada por los dominantes para justificar su dominación.

El complejo de inferioridad entre los colonizados, afirma Fanon, es un fenómeno recurrente; entre los garífunas se expresa en su deseo de igualarse o superar al ladino, pues este último, en general, se cree superior al indígena y al garífuna. Para contrarrestar tal efecto, algunos garífunas pregonan con orgullo el conocimiento de su propia historia y de su origen, cosa que no pueden presumir los ladinos. Y ante «los otros negros» su conducta es parecida, ellos se reivindican como guerreros contra la opresión, al tiempo que acusan a los guiou de haberse mantenido en la esclavitud. 
El caso más narcisista, siguiendo los términos de Fanon, es el movimiento rasta, que propugna un odio generalizado a los «caras pálidas, todos los que no son negros», llegando incluso a llamarlos «inditos», expresando así un modo despectivo y profundamente interiorizado en Guatemala para demeritar a los otros —indígenas y ladinos.

Los rastas reivindican el lugar del negro en la genealogía bíblica. En sus comienzos en Jamaica, el rastafarismo estableció, entre otros principios, el rechazo hacia la raza y cultura blancas, la preparación del retorno a África y la superioridad de la raza negra. Como Scott (2004: 252) lo planteaba, «el respeto y el conformismo explícitos ante los deseos de los poderosos son instrumentos absolutamente indispensables de sobrevivencia», uno podría sin duda hablar de «enajenación», «exceso de control y tendencias agresivas que se pueden descubrir en el discurso oculto»; es así como algunos llenos de resentimiento suelen asaltar a turistas, crear conflictos contra los ladinos, a la vez que desean una novia gringa.

Contradictoriamente, se ven envueltos entre la admiración y el odio, tal vez ansia de venganza, como apuntaba Fanon (1973: 52): «Acaricio estos senos blancos con mis manos ubicuitarias y hago mías la civilización y la dignidad blancas». Scott mencionaba que el dominado hace lo posible por romper con el estereotipo impuesto, usando cremas blanqueadoras o alisándose el cabello; como apuntó Taylor, los otros pueden lograr cultivar una imagen negativa de uno mismo. Entre los garífunas, además de existir estas prácticas de belleza, como alisarse el cabello, el común se vive también como los «más blanquitos» respecto a los guiou, así como a los culíes, que «son como morados». Igualmente, este sentimiento hacia los guiou es contradictorio, por una parte son nosotros, porque también pertenecen a «la raza negra», pero al cabo son otros; sin embargo, tal vez por hablar inglés pueden ser admirables. En Belice, la distinción entre un garífuna y un creole es evidente: el garífuna es más feo, según algunos hispanos y culíes; en Livingston, el garífuna es menos moreno que el creole, según algunos ladinos.

Así, observamos que la expresión de la colonización interna, como la llama Fanon, o la dominación, como la denomina Scott, es parte de un círculo vicioso procurado por los dominantes, en el cual los dominados o colonizados reproducen sin darse cuenta porque están enajenados de sí mismos. A pesar de que existen los discursos ocultos que sirven para aminorar la situación de subordinación, en general, los 
dominados reproducirán los discursos y actos de los dominantes cuando se dé la ocasión entre los propios dominados. La liberación, como lo señaló Fanon, requiere del darse cuenta de esta situación de colonización o dominación interna para procurar un cambio.

En Belice, los garífunas están reconocidos como pueblo indígena, además de gozar con una importante presencia en poblados como Dangriga y Punta Gorda. En Guatemala, los garífunas tienen el mismo estatus que se contradice con la idea de ser indígena para los garífunas y para los connacionales en general; y como señalaba Ellington hace una década, su autopercepción no coincide con esta categoría aun en la actualidad. Bajo este entendido, los garífunas han aceptado jugar el papel «indígena» en los ámbitos públicos u oficiales, y esto se puede interpretar paradójicamente como un acto de resistencia, pues se puede observar como una actuación que se acompaña de un tipo de discurso oculto. En el acto público aceptan ser indígenas, pero dentro de la comunidad lo rechazan o lo cuestionan.

\section{CONCLUSIONES}

La historia no oficial no solo refleja el punto de vista de los subalternos o dominados, sino que tiene valor en cuanto a que conforma un discurso sobre identidad. El discurso histórico se convierte en un instrumento ideológico político como cuando los garífunas reclaman una indemnización al imperio inglés por los efectos de la diáspora. La historia incluye a unos y excluye a otros, es así un discurso de poder que coloca a los garífunas como guerreros libertarios.

La identidad es también conformada por los otros; si un pueblo colonizado o dominado tiene la necesidad de tener una historia propia es porque los otros - dominantes - les han dado una participación en la suya y entonces deben apoyarla o refutarla.

En los pasajes de la propia historia, la valoración de la conducta de los personajes históricos es positiva, parece no haber contrarios a las decisiones de los líderes, el enemigo es inglés, de la misma manera que en la actualidad en lo cotidiano el antagónico es «blanco».

Contradictoriamente, como hemos observado, en el ser garífuna se encuentra también contenida la voz más silenciosa, el indígena es parte del ser garífuna, está en su historia como lo está en su sangre, y aunque a veces sea difícil aceptarlo porque es una 
figura que conforma otra identidad, el ser indígena abre en la actualidad algunas posibilidades, como la obtención de recursos económicos para determinados proyectos que las instituciones gubernamentales financian si los beneficiaros son «indígenas». Sin embargo, si se consideran las palabras de Taylor en cuanto al reconocimiento - político-, en el caso de los garífunas como parte de la nación guatemalteca, este discurso constituyó un paso fundamental de la nación que les hizo reflexionar sobre la propia identidad y responder que si bien tienen ascendencia indígena no se autoidentificarían como tal, salvo para determinados fines. El uso de los discursos identitarios es relacional, siempre responde a algo. Su historia, pensada como un reciente ayer, responde claramente al momento — posterior a la firma de los Acuerdos de Paz (1996) - en que políticamente se reflexionaba sobre el lugar que los garífunas, y los indígenas en general, ocuparían en una nación que desde ese momento se reconocía multicultural y plurilingüe.

Asimismo, dar a conocer el origen mediante la oralidad reafirma otro rasgo importante de identidad que unifica. Colocarse como un pueblo africano que desde un primer momento supo lo que le convenía al aliarse con los caribes aumenta la autoestima de un pueblo subordinado; de esta manera, el subrayar «nosotros nunca fuimos esclavos» cobra mucho sentido, pues además de marcar una diferenciación con los otros negros también afirma un valor de resistencia presente desde entonces. El reconstruir la historia propia tiene que ver con tomar una postura ante el hecho de la dominación histórica de los europeos sobre los africanos y los americanos, de la condición de colonizados.

$\mathrm{Su}$ historia, no conclusa todavía, comprende el vivir en un continuo exilio ideológico, pues no termina de encajar en la nación guatemalteca. Para algunos pareciera ser irrelevante dejar Livingston, donde llevan alrededor de doscientos años, e irse a Estados Unidos, adonde muchos se fueron aproximadamente hace cincuenta años; para un pueblo desterrado que ha vivido el exilio, su lugar para habitar es simbólico hasta cierto punto, ya que los ancestros, lo que da continuidad a su identidad, están siempre con ellos, en otro lugar que no es tangible, como los sueños.

Por otro lado, el pensar a los garífunas como parte de un mundo dominado por un referente ideológico «blanco»y «occidental» también permite comprender por qué puede haber un rechazo hacia lo indígena, así como por qué es importante para ellos 
marcar las diferencias con los guiou. Del mismo modo, siguiendo la ruta del círculo vicioso del racismo y la dominación, se entiende por qué entre los dominados se da también la dominación: por un reflejo de imitación, según Scott; por una interiorización del blanco, como dice Fanon.

Así, tanto el discurso histórico como algunos actos oficiales de los garífunas de cara al gobierno son de resistencia, surgidos desde su condición de dominados y por los resquicios de momentos pasados del colonialismo; consecuencias, continuidades, como ocurre en toda América Latina. 


\section{BIBLIOGRAFÍA}

Adams, Richard y Santiago Bastos, 2003, Las relaciones étnicas en Guatemala, 19442000. CIRMA, Guatemala.

Arrivillaga, Alfonso, 1988, «Documento para el estudio de la historia popular de los caribes negros de Livingston, Guatemala». Tradiciones de Guatemala, núm. 30. CEFOL, USAC, Guatemala.

2006, Marcos Sánchez Díaz: ahari, fundador y protector de Gulfu Iyimou (Labuga), Nojib'sa, Guatemala.

Ciudadanías trasnacionales en la diáspora garífuna, mimeo.

Bonfil Batalla, Guillermo, 1995, «Historias que no son todavía historias». En Historia ¿para qué? Editorial Siglo XXI, México.

1996, «La Teoría del control cultural». Acta Sociológica, núm. 18, septiembrediciembre. FCPyS, UNAM, México.

Casaús Arzú, Marta Elena, 2000, «En busca de la identidad perdida: reflexiones en torno a la consulta popular para las enmiendas de la constitución». En Desarrollo y diversidad cultural en Guatemala, editado por Marta E. Casaús y Juan Carlos Gimeno. Universidad Autónoma de Madrid, Agencia Española para la Cooperación Internacional, Cholsamaj, Guatemala.

Cassá, Roberto, 1992, Los indios de las Antillas. Colección Indios de América. Editorial MAPFRE, Madrid, España.

Césaire, Aimé, 1969, Cuaderno de un retorno al país natal. Agustí Bartra (tr. y pról.). Ediciones Era, México. 
Ellington Lambe, Gerardo, 1989, «La minoría negra en relación a las configuraciones étnicas». Exposición realizada en el seminario Estado y Clases Sociales, México.

Fanon, Frantz, 1973, Piel negra, máscaras blancas. Editorial Abraxas, Buenos Aires.

2003, Los condenados de la tierra. FCE, México.

Gargallo, Francesca, 2002, Garífuna Garínagu, Caribe. Historia de una nación libertaria. Gobierno del Estado de Quintana Roo, Siglo XXI, México.

Gilly, Adolfo, 1995, «La historia como crítica o como discurso del poder». En Historia ¿para qué? Editorial Siglo XXI, México.

Kymlicka, Will, 2002, «Del Estado nacional al Estado multinacional». En Democracia, ciudadanía y diversidad: el debate político. PNUD, Guatemala.

Lowell, James, 2002, «The Origin of the Garifuna». En http://www.garinet.com [consultado el 18 de mayo de 2003].

Martínez Peláez, Severo, 1987, La patria del criollo. Ensayo de interpretación de la realidad colonial guatemalteca, 8. ${ }^{\text {a }}$ edición. Universidad Autónoma de Puebla, México.

Organización Negra Centroamericana, ONECA, 2000, «Declaración de la cumbre continental de los pueblos afroamericanos frente al desarrollo económico, político y social, y contra el racismo y la discriminación», 27-30 de noviembre. La Ceiba, Honduras.

Rogozinski, Jan, 1999, A Brief History of the Caribbean. From the Arawak and Carib to the Present, edición revisada. Facts on File, USA. 
Scott, James C., 2004, Los dominados y el arte de la resistencia. Discursos ocultos. Ediciones Era, México.

Suazo E., Salvador, 1997, Los deportados de San Vicente. Editorial Guaymuras, Tegucigalpa, Honduras, C. A.

Taracena, Arturo et al., 2002, Etnicidad, estado y nación en Guatemala, 1808-1944, vol. I. CIRMA, Guatemala.

Taylor, Charles, 2001, El multiculturalismo y «la política de reconocimiento». FCE, México.

Taylor, Douglas, 1935, «The Island Carib of Dominica, B. W. I.». American Anthropologist, vol. 37, núm. 2, Nueva York.

Fecha de recepción: 25 de octubre de 2008.

Fecha de aceptación: 1 de julio de 2009. 